\title{
Differences of Radiographic Quality and Exposure Index on Computed Radiography Using Imaging Plate with Different Reading Time Period
}

\author{
Authors \\ Dartini, Ary Kurniawati, Andrey Nino Kurniawan, Sugiyanto, Fatimah, \\ M. Irwan Katili , 1,2,3,4,5 \\ ,1,2,3,4,5 Politeknik Kesehatan, Kemenkes Semarang, \\ Jl. Tirto Agung Pedalangan, Banyumanik, Semarang 50239, Indonesia \\ Email:Dartini.tini@gmail.com
}

\begin{abstract}
Introduction: Computed Radiography $(C R)$ is the process of digitizing images using photostimulable plate to acquire image. The energy stored in the imaging plate disappears over the time, so imaging plate should be read as soon as possible to avoid the loss of image information.

Objective: This study aimed at determining the profile of Exposure Index (EI), radiographic density and contrast on radiographs produced using $C R$ with various reading time: 0 hours (without a break), 2, 4, 6 , $8,10,12,14,16,18,20,22$ and 24 hours after exposure.

Methods: The type of research is observational study with cross-sectional design where data were collected by survey and analyzed using descriptive analysis.

Result: The results showed that the profile of the exposure index (EI) value decreased irregularly. The average value of the highest and lowest EI on each object were 1394.33 and 1127.67 (cranium), 1871.33 and 1573.33 (elbow joint), while the largest percentage of degradation was at 22-hour reading time.

Conclusion: The profile of radiographic density and contrast values varied at each lag time. The highest contrast were 1.24 (cranium) and 0.40 (elbow joint) that resulted at 0 hours lag time, whereas the lowest contrast value where 0.81 (cranium) and 0.34 (elbow joint) that resulted at 16 hours lag time. The image contrast was still editable till 10 hours lag time (cranium) and 12 hours lag time (elbow joint).

Keywords: exposure index, computed radiography, radiographic quality.
\end{abstract}

\section{INTRODUCTION}

Computed Radiography is the process of digitizing an image using a sheet or photo stimulable plate for the acquisition of image data. Computed radiography (CR) uses equipment very similar to conventional radiography except that Computed Radiography uses Imaging Plate (IP) made of phosphorus rather than film (Ballinger, 2003).
The energy stored in the imaging plate disappears from time to time that imaging plate should be read as quickly as possible to avoid losing image information (Christi, Beth, 2010). Latent images will lose about 25 percent of energy in 8 hours so it is important to process the tape immediately after exposure (Carlton and Adler, 2001).

The quality of the radiograph is the ability of the radiograph to produce a clear picture of an 
anatomical structure on a radiograph. High quality radiographs are needed to determine the exact diagnose by a radiologist (Bushong, 2001).

Index exposure (EI) is a measure of the amount of exposure received by the image receptor (IR) that depends on the radiation field area and the scattering rays indicating the image quality. That's why, equipment manufacturers provide various EI recommended for optimum image quality.

Based on the preliminary survey, many radiographers do not directly perform the reader after the examination and often accumulate cassettes that have been exposed. Based on the above background, researchers are interested to conduct a study by analyzing the results of radio diagnostic images between the one performs the reader directly with the one performs the reader indirectly after the examination.

\section{METHODS AND MATERIALS}

The type of research is observational with cross sectional approach. The research design used was survey design with observation data collection technique.

Figure 1, Theoretical Framework

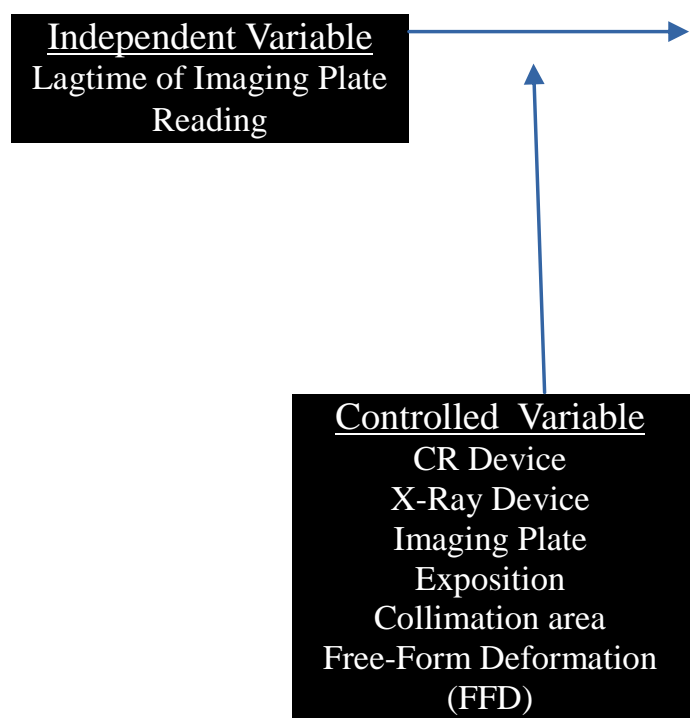

Dedependent Variable

Index Exposure

Density \& Contrast
The population in this study is imaging plate of all sizes while the samples are 6 pieces imaging plate with size $24 \times 30 \mathrm{~cm}$ used to make the radiograph AP projection cranium and AP elbow joint using phantom and being read with time lag (without time lag) 0, 2, 4, 6, 8, 10, 12, 14, 16, 18, 20, 22 and 24 hours with each lag time group using 3 imaging plates.

The method used is the observation of the image of the result by giving the time lag of the imaging plate readings from the expose time i.e, direct reading without time lag, pause $2,4,6,8,10,12$, $14,16,18,20,22$ and 24 hours.
Analysis of data used to describe each independent variable and dependent variable is presented in table of frequency distribution and graph. 


\section{JMSCR Vol||05||Issue||06||Page 23664-23669||June}

RESULTS AND DISCUSSIONS

Figure 2 Radiographic Image Samples of Cranium Objects and Elbow Joint

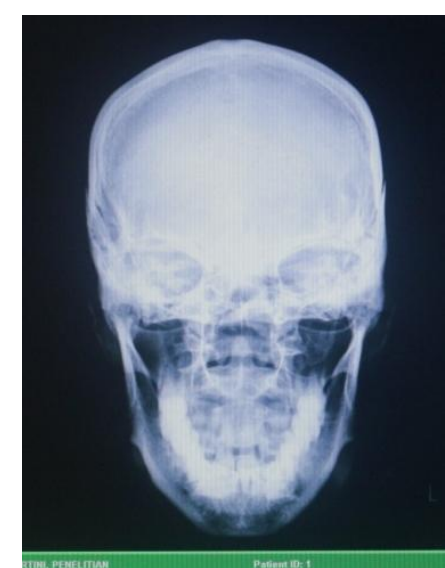

0 hour

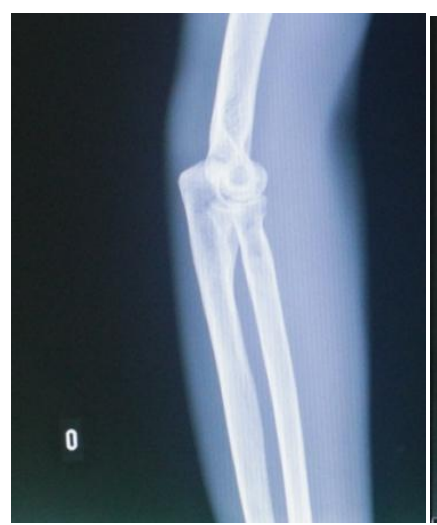

0 hour

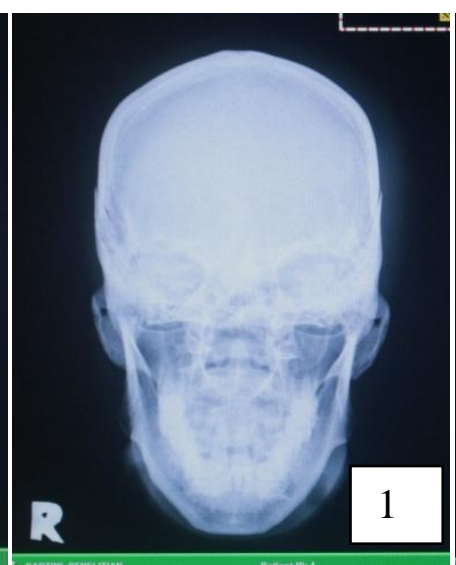

16 hours

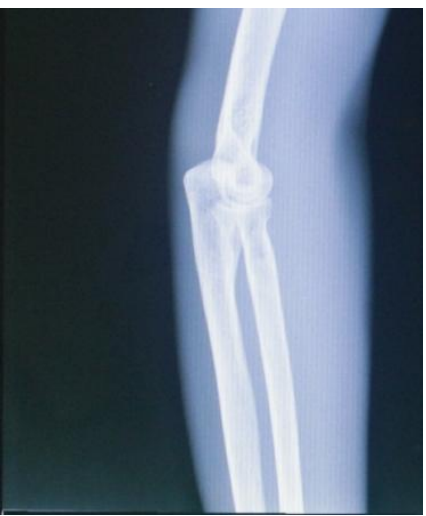

16 hours

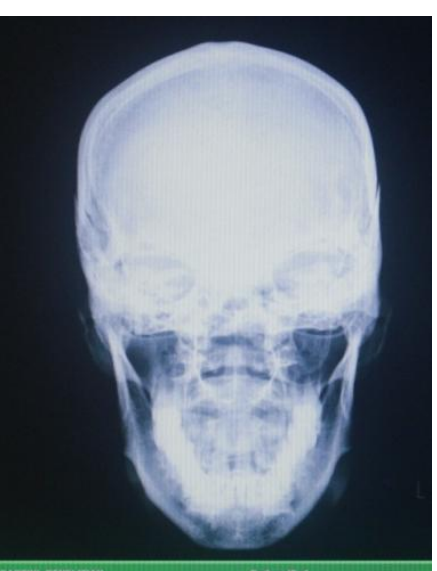

22 hours

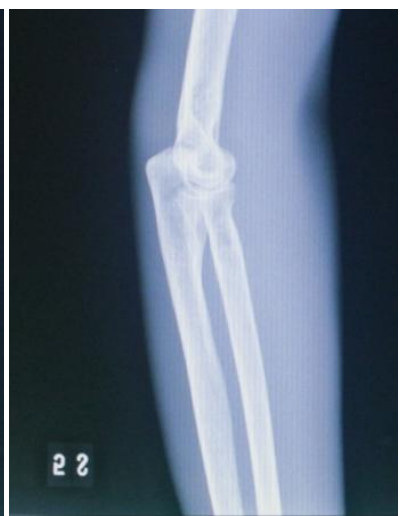

22 hours

An Overview of the Index's Exposure Value Against the Time Lag

Figure 3 Average value of EI against the time lag

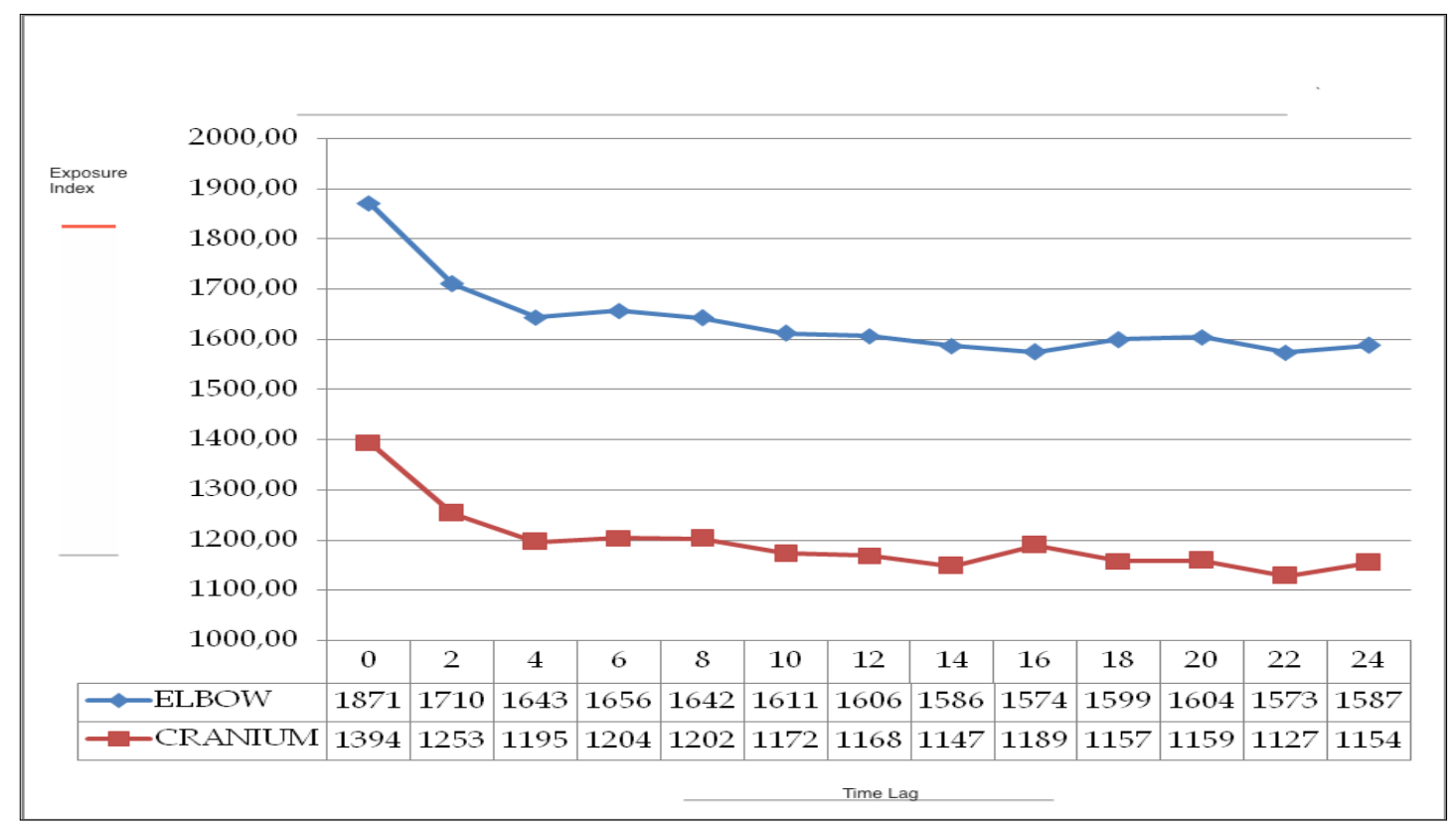




\section{JMSCR Vol||05||Issue||06||Page 23664-23669||June}

Figure 4 Percentage decrease in mean value of EI against the time lag

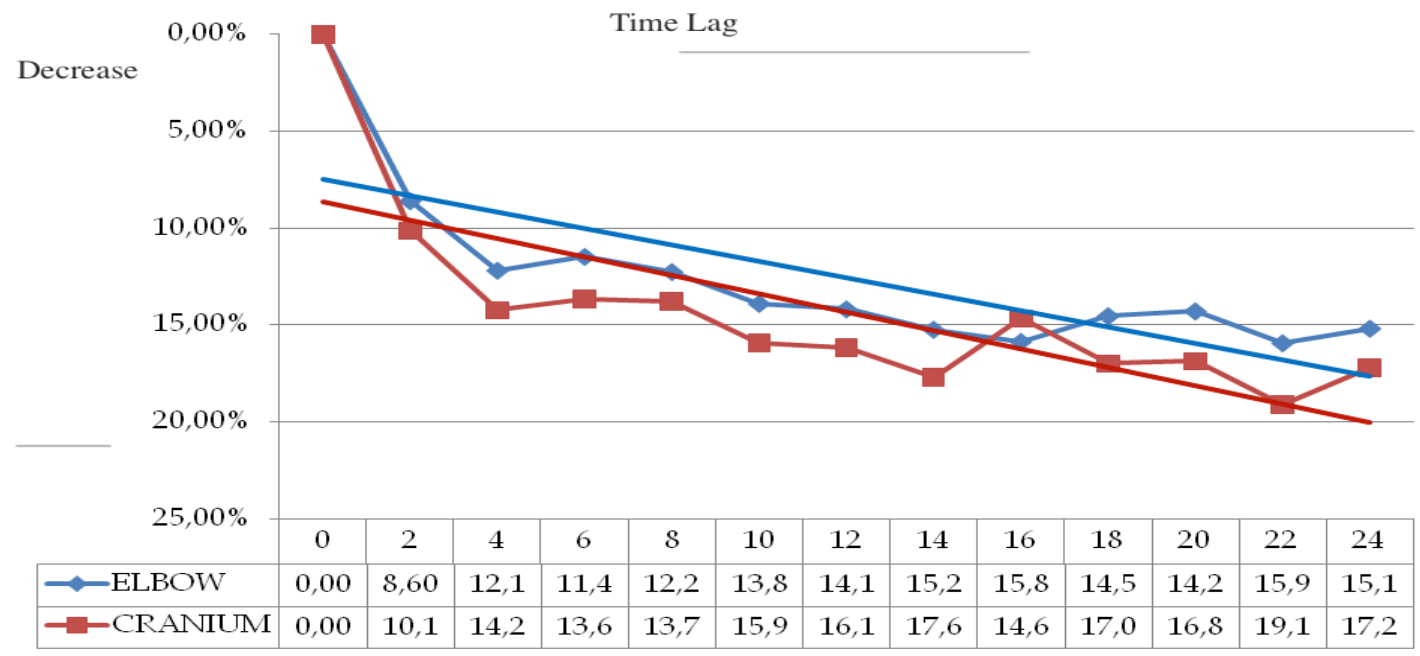

Figure 2 and Figure 3 present Index Exposure on the resulting image using Computed Radiography were reading of Imaging Plate is directly performed after exposure without pause (0), with pauses, 2, 4, 6, 8, 10, 12, 14, 16, 18, 20, 22 and 24 hours after exposure to the cranium object and elbow joint. The results showed that the largest average of EI value was in the 2 objects at the time interval of 0 hours and the smallest EI average value was at a time interval of 22 hours. The standard deviation was greater in the elbow joint object compared to the cranium object and there was also a decrease in the value of EI from the original or the pause 0 to the EI using different reader times but the decrease was not stable as the reader time increases. This supports Carter and
Veale (2010) that the energy stored in the imaging plate disappears over time. Furthermore, the results from time to time indicated downs and some ups. This can be caused, among others, the existence of different cassette life and also be influenced by the electrical voltage instability when exposure was made. Christi (2010) also conveyed that the energy stored in imaging plates disappears from time to time. But the percentage of decline is not as great as presented by Carlton and Adler (2001) who mentioned that Image Latent will lose about 25 percent of energy in 8 hours, so it is better that Imaging Plate time readings are done immediately after the exposure.

Description of Density and Contrast Values on Radiography with Time Lag

Figure 5 Graph of contrast values against time lag

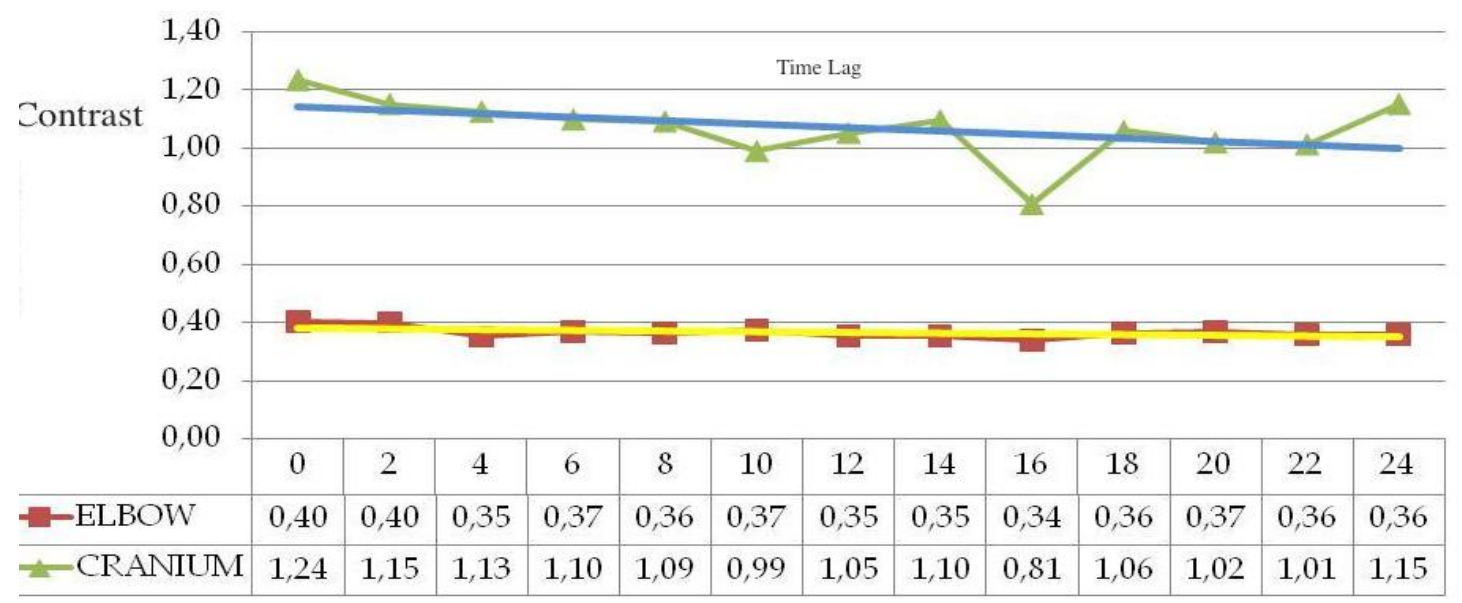


The results showed that the highest density value is on the sample 1 (2.27) and the lowest density value in the sample no 2 and no 4 (0.84) where from each increase time lag there happened inconsistent density value. This supported Christi (2010) that the energy stored in the imaging plate disappears over time so that with the disappearance of energy in the plate over time before the reader will affect the density generated on the radiograph.

The results of the contrast study show that the contrast value in the picture obtained with the reader time lag, the highest contrast value in the sample image no 1 (cranium 1$)=1.25$ and the lowest contrast in the sample no. 4 (elbow 1) = 0.32 . The result of the contrast value on the image generated by the reader time lag is also inconsistent which also supported Christi (2010) that he energy stored in the imaging plate disappears over time so that with the disappearance of energy in the plate over time before the reader will affect the value of contrast generated on the resulting image. This is due to the condition of imaging plates that have different ages and possibly can be caused due to the flow of electricity into the plane that is not stable.

Description of Editable Radiographic Image Generated by the Time Lag

Table 1, Check list of elbow joint radiograph editing

\begin{tabular}{|l|c|c|c|}
\hline NO. & $\begin{array}{c}\text { Time } \\
\text { Lag }\end{array}$ & $\begin{array}{c}\text { NOISE } \\
\text { (YES) }\end{array}$ & $\begin{array}{c}\text { NOISE } \\
\text { (NO) }\end{array}$ \\
\hline 1 & 0 & $\mathrm{~V}$ & \\
\hline 2 & 2 & $\mathrm{~V}$ & \\
\hline 3 & 4 & $\mathrm{~V}$ & \\
\hline 4 & 6 & $\mathrm{~V}$ & \\
\hline 5 & 8 & $\mathrm{~V}$ & \\
\hline 6 & 10 & $\mathrm{~V}$ & \\
\hline 7 & 12 & $\mathrm{~V}$ & \\
\hline 8 & 14 & $\mathrm{~V}$ & \\
\hline 9 & 16 & & $\mathrm{~V}$ \\
\hline 10 & 18 & & $\mathrm{~V}$ \\
\hline 11 & 20 & & $\mathrm{~V}$ \\
\hline 12 & 22 & & $\mathrm{~V}$ \\
\hline 13 & 24 & & $\mathrm{~V}$ \\
\hline
\end{tabular}

Table 2 Check list of radiograph cranium editing

\begin{tabular}{|l|c|c|c|}
\hline NO. & Time Lag & $\begin{array}{c}\text { NOISE } \\
\text { (YES) }\end{array}$ & $\begin{array}{c}\text { NOISE } \\
\text { (NO) }\end{array}$ \\
\hline 1 & 0 & $\mathrm{~V}$ & \\
\hline 2 & 2 & $\mathrm{~V}$ & \\
\hline 3 & 4 & $\mathrm{~V}$ & \\
\hline 4 & 6 & $\mathrm{~V}$ & \\
\hline 5 & 8 & $\mathrm{~V}$ & \\
\hline 6 & 10 & $\mathrm{~V}$ & \\
\hline 7 & 12 & & $\mathrm{~V}$ \\
\hline 8 & 14 & & $\mathrm{~V}$ \\
\hline 9 & 16 & & $\mathrm{~V}$ \\
\hline 10 & 18 & & $\mathrm{~V}$ \\
\hline 11 & 20 & & $\mathrm{~V}$ \\
\hline 12 & 22 & & $\mathrm{~V}$ \\
\hline 13 & 24 & & $\mathrm{~V}$ \\
\hline
\end{tabular}

The result of the research that it is possible to do the editing on the result of the radiograph produced by the time lag of the reader on the sample of elbow joint object in the 12 hour reader range is still possible to do the editing with almost the same result with the reader directly or no lag time, while at intervals of 14 hours up, although the editing of the noise still looks clear but it disturbs the radiographic picture of the elbow joint. While on the sample of cranium object the result is in the range of reader 10 hours is still possible to do the editing with results similar to the direct reader or while at intervals of 12 hours upwards despite the editing noise still looks clear but it disturbs the images cranium radiograph According to Papp (2006) editing works aimed at increasing the recorded detail and also eliminating the black and white pixels that affect the diagnostic information. But with editing it can also increase the noise / artifacts so that there must be a radiograph limit for editing that produces high detail but the noise can be tolerated which does not interfere with the diagnostic information of a radiograph. Therefore, the reader should still be done as soon as possible so that imaging palate does not lose energy before being read.

\section{CONCLUSIONS}

The value of exposure index (EI) during imaging experienced the decrease in line with lag time despite the decline was unstable, where the highest and lowest of EI averages on each of 
the cranium 1394.33 and 1127.67 , the elbow joints 1871.33 and 1573.33 while the the greatest percentage of decrease was in the lag time of 22 hours. The density and contrast values vary greatly in each time lag, the highest contrast was 1.24 on the cranium object and 0.40 on the elbow joint object resulting from the time lag 0 and the lowest contrast in cranium $=0.81$ and in the elbow joint $=0,34$ which occurs in the 16-hour reader time interval. The radiographs are still possible to do the editing at intervals of 12 hours for elbow joint object and time lag 10 hours for cranium object.

\section{DAFTAR PUSTAKA}

1. Ballinger, P.W, 2003, Radiographic Positions and Radiologic Prosedures, Mosby Inc., Missouri..

2. Bushong, Steward C. 2001. Radiographic Science For Technologist Physics,Biology, and Protection. Amerika Serikat : Mosby inc.

3. Carlton, Ricard R, and Adler, Arlene M. 2001. Principles of Radiographic Imagin : An Art and A Science. Amerika Serikat : Delman

4. Carter,C, Veale,B. 2010. Digital Radiography and PACS. Mosby Missouri.

5. C. Cristi, Digital Radiography and PACS, Mosby Elseiver, St. Louis, Missouri, 2010

6. Papp, Jefray. 2006. Quality Management in the Imaging Science. United States of America. 